\title{
LECTURAS CASUALES: ENRIQUE VILA-MATAS Y SUS VÍNCULOS TRANSATLÁNTICOS
}

\author{
CASUAL READINGS: ENRIQUE VILA-MATAS \\ AND HIS TRANSATLANTIC CONNECTIONS
}

\section{FRANCISCA NOGUEROL JIMÉNEZ*}

\section{RESUMEN}

El presente artículo analiza las estrechas relaciones existentes entre Enrique Vila-Matas y algunos de los autores latinoamericanos más significativos de los últimos años, destacando cómo en la otra orilla atlántica se supo apreciar muy pronto la profunda originalidad de una escritura signada por la atención al detalle, la reflexión metaficcional, la hibridez, la intertextualidad y los juegos con la identidad.

Palabras clave: Enrique Vila-Matas, estudios transatlánticos, metaficción, hibridez, autoficción.

\section{ABSTRACT}

This article analyzes the important links between Enrique Vila-Matas and some of the most significant Latin American authors of the latest years. It emphasizes how the transatlantic writers did not take long to appreciate the deep originality of Vila-Matas, a writer defined by his attention to details, metafictional reflection, hybridity, intertextuality, and autofiction.

Keywords: Enrique Vila-Matas, transatlantic studies, metafiction, hybridity, autofiction.

Recibido: 04.12.15. Aceptado: 08.07.16.

* Profesora Titular de Literatura Hispanoamericana, Universidad de Salamanca. España. Correo electrónico: fnoguerol@usal.es 
$\mathrm{E}$ NRIQUe VILA-Matas es responsable de un capítulo fundamental en la historia de la literatura contemporánea. Así lo revela, por ejemplo, el hecho de que fuera citado en dos importantes novelas aparecidas en 2009 -Invisible de Paul Auster, y Nocilla Lab de Agustín Fernández Mallo, responsables de aumentar el mito sobre el escritor-, o sus más recientes premios literarios -Formentor de las letras 2014 y FIL de Literatura en Letras Romances 2015, en ambos casos concedidos por toda su obra narrativa. Y es que hay un tono, una voz y una ironía característicos en su obra, signada por su escritura detallista y compleja, sofisticada y cargada de dudas. En este sentido, aunque la nómina de creadores que aborda y lo abordan en sus escritos es inmensa, en estas páginas pretendo centrarme en los autores latinoamericanos con los que comparte ars poética. Es el caso de maestros como Augusto Monterroso, Sergio Pitol o Alejandro Rossi; compañeros como Ricardo Piglia y Roberto Bolaño; y discípulos aventajados como Rodrigo Fresán, Alan Pauls, Sergio Chejfec, Alejandro Zambra o Leonardo Valencia, por nombrar unos pocos.

Así se explica el título de este trabajo: con lecturas casuales deseo hablar de la lectura de y sobre Vila-Matas entendida como placentero encuentro, relacionada con actividades tan propias del autor como el paseo o la vagancia del flâneur, regida por la libertad y la antisolemnidad, pero que, en ningún momento, renuncia a indagar sobre los lazos existentes entre vida y literatura. Siguiendo el presupuesto emersoniano, en los creadores de su estirpe la escritura procede de la propia literatura. Causalidad y casualidad llevan, así, al establecimiento de relaciones profundas -en muchos casos de amistad real, como ocurre en el caso de nuestro autor con Pitol, Bolaño o Fresán-, pero que devienen especialmente relevantes a través de las mutuas lecturas.

Para comenzar mi exposición, reseñaré un hecho fácilmente comprobable: su amor a Latinoamérica se ve reflejado en sus visitas continuas al subcontinente, en los escritores que ha descubierto al público internacional -así ha sucedido, por ejemplo, con Enrique Prochazka, Sergio Chejfec o Leonardo Valencia-, o en los blogs que aconseja en su página web, entre los que ocupan un lugar estelar los comentarios de Christopher Domínguez Michael o los de "Moleskine literario" de Iván Thays. Y es que Vila-Matas se integra en una categoría de escritores marcados por el universalismo. Como él mismo apuntó en "Inventar lo real" (2007), ponencia presentada en el IV Congreso Internacional de la Lengua Española: "Pertenezco a un tipo de autor que no cree en la división entre escritores latinoamericanos y españoles. Todos habitamos la misma lengua. Yo hace años ya que siento 
que crucé todas esas fronteras". Su condición trasnacional es subrayada de nuevo por Fernando Iwasaki (2010): "Enrique Vila-Matas es, sin asomo de duda, el autor español más influyente entre los nuevos narradores latinoamericanos, y junto con Javier Marías es el escritor español más prestigioso a nivel europeo. De hecho, Vila-Matas es definido como 'el más latinoamericano de los autores españoles' o como 'el más europeo de los escritores españoles'”.

De hecho, la originalidad de su obra fue apreciada antes en América Latina que en España. Así, el reconocimiento le llegó, en primer lugar, de países como Argentina o México, como destaca Juan Villoro en "Los shandys del Templo Mayor" (2004):

Con la disposición cosmopolita que suelen tener los países a los que cada libro llega revestido de la magia de lo excepcional, Vila-Matas fue aceptado en México como un clásico instantáneo que combinaba los estímulos de radicales de la letra, muy disímiles entre sí, pero asimilados a una misma estirpe gracias al más reciente de ellos. ¿Qué hay en común entre Hemingway, Monterroso, Perec y Bradbury? La mirada de Enrique Vila-Matas. [...] "Originalidad, cuestión de estómago", escribió Valéry [...] Recordé entonces una nota precursora donde Âlvaro Enrigue llamaba a Vila-Matas "mito naciente de la literatura española". Por esos días, Christopher Domínguez Michael inició su sostenida vindicación del conspirador shandy. Âlvaro Mutis, Alejandro Rossi, Sergio Pitol y Augusto Monterroso se unieron a la celebración del imaginativo VilaMatas. Mientras tanto, en España, el insólito fabulador mantenía un rango minoritario que pactaba bien con el misterio y la clandestinidad.

Atendiendo a estos presupuestos, se comprenderá que, en el periodo de publicación de sus primeros libros, se encontrara más interesado por las literaturas latinoamericanas que por la española, apreciando las vías en las que las primeras transgredían las fronteras ficcionales frente al costumbrismo y realismo que continuaban gravando la novela peninsular. Como él mismo destaca en entrevista con Bernardo Esquinca (2003): "En mi país, en España, ocurre que, como decía el añorado Monterroso, ficción y realidad siguen siendo cosas diferentes. Sin embargo, yo estoy más cerca de una literatura latinoamericana en la que realidad y ficción están tan imbricadas que es muy común vivir en las dos a la vez, o bien pasar tan sutilmente de una a otra que los términos se confundan".

Así, se ganó a pulso el calificativo por el que Bolaño -incluyendo en el tándem a Javier Marías- lo tildó de uno de "los herederos primogénitos del 
boom" (Pinto, 2001). Incluso ha sido asimilado al savoir faire de alguna literatura nacional latinoamericana, como leemos en Rodrigo Fresán (2001):

[...] Alguna vez escribí que una forma más tonta que extraña de definir a Vila-Matas sería afirmar que se trata del más argentino de los escritores españoles. Después de todo, allí están la manía referencial y el siempre dúctil aparato enciclopédico, el humor en serio, los juegos metaficcionales donde el autor es siempre protagonista, las apelaciones cómplices a su lector, y el tránsito cosmopolita, constante y sin compromiso, por las bibliotecas y las ciudades.

Pero, como ya apunté arriba, no será Argentina su única "patria cultural". De hecho, si con alguien reconoce Vila-Matas una eterna deuda es con el mexicano Sergio Pitol, a quien calificará como "un lujo de Veracruz"-de donde él mismo postula ser originario en homenaje al maestro- y al que supo definir como "un Cervantes extraordinario":

[...] Cuando conocí a Sergio, en Varsovia, yo tenía 25 años, y en España ningún escritor de su categoría me concedía un minuto ni me dedicaba tiempo para hablarme de literatura. Así que el magisterio de Sergio se dio, desde el primer momento, en la conversación en la sobremesa en su casa de Varsovia, a mi paso por esa ciudad. Fui a Varsovia inocentemente y me convertí en escritor gracias a Pitol y mi afición definitiva por la cultura la produjo el propio Sergio [...] (2006) ${ }^{1}$.

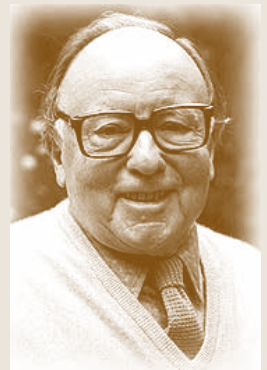

A. Monterroso

Del mismo modo, Vila-Matas siente fervor por Monterroso, otro gran raro con el que aprendió a degustar dietarios a partir de títulos tan vilamatianos como Movimiento perpetuo, La palabra mágica y La letra e: fragmentos de un diario, y sobre el que apuntó con amargura en "Monterroso, en nueve palabras" (2004b): "No le dieron el premio Cervantes los tarugos de siempre. Porque no era solemne ni engreído. Y porque no había escrito, decían, sus Obras Completas".

\footnotetext{
${ }^{1}$ A esto le responde Pitol, con la modestia que le caracteriza, en "El Rómulo para Enrique":

"El 6 de julio de 2001, por la mañana, me enteré de que el Premio Rómulo Gallegos había sido adjudicado a uno de los escritores que más admiro y quiero, el español Enrique Vila-Matas. Lo conozco desde hace más de treinta años, aún antes de iniciarse en las letras, jovencísimo, y he seguido todo su trayecto, desde sus complicados experimentos iniciales hasta sus perfectas 6 obras de los últimos años. Considero su amistad como un don extravagante y majestuoso de los dioses. [...]. Lo consideraba como mi secreto hermano gemelo, mi colega de aventuras, de lecturas, de viajes, hasta que hace dos años esa relación se transformó. Con sus últimos libros, Enrique se transformó en mi maestro. A veces sueño que lo visito y lo saludo llamándole Sire [...]” (2001).
} 
Pasemos ya a ocuparnos de la canonización literaria de nuestro autor, lo que Christopher Domínguez (2008) considera un acto de afirmación generacional en ambas orillas del Atlántico:

[...] Durante veinte años, en América Latina (Álvaro Enrigue, Roberto Fresán, Alan Pauls, Juan Villoro, Bolaño, Roberto Brodsky) y en España (Mercedes Monmany, Masoliver Ródenas, Ignacio Echevarría, José María Pozuelo Yvancos), hemos sido los críticos y los escritores nacidos en la segunda mitad del siglo XX quienes hemos respaldado a Vila-Matas, un autor que entusiasma menos cuando se trata de lectores mayores, excepción hecha de Sergio Pitol [...].

Pero serán los autores nacidos a partir de los años sesenta quienes mostrarán más claramente su impronta: desde los ya citados Padilla, Fresán, Iwasaki o Zambra a Santiago Gamboa, Thays o Valencia. En las reseñas entusiastas que éstos dedican al universo vilamatiano se reflejan algunas constantes especialmente admiradas, que serán debidamente desarrolladas en la segunda parte de este ensayo:

1) Sus textos se presentan más en potencia que en acto, iluminando cuestiones teóricas de absoluta actualidad -juegos entre ficción y realidad, muerte del autor y del concepto tradicional de literatura, esencial rol del lector, hibridismo genérico- sin olvidar en ningún momento el cuidado de la forma.

2) Defienden un canon atípico, en el que el propio escritor se incluye y que reconoce tanto en libros de ficción como en ensayos. Así, para Christopher Domínguez (2008), “[...] le ha dado orden y concierto a una literatura $[\ldots]$. Se trata de una escuela del gusto [...]. Escritor canónico y hombre representativo del cambio de siglo [...], se le puede halagar diciéndole que no es tanto el autor de una obra como el padre de una literatura, viejo y hermoso elogio"2.

3) Reflejan de forma excepcional los entresijos del mundo de la literatura. Como subraya Piglia en "Leyendo a Enrique Vila-Matas" (2011):

\footnotetext{
${ }^{2}$ En esta misma línea se situó Guadalupe Nettel (2008) al presentar Dietario voluble en la ciudad de México: “[...] Lo que sucedió con Vila-Matas fue [...] que el mundo se adaptó a su obra, a su prosa rara e inclasificable, al punto en que acabó por crearse el vilamatismo. De ser extraños, sus libros pasaron a ser un paradigma de esa nueva literatura que se inclina por los géneros híbridos. Se volvió inconfundible su estilo omnívoro que todo lo convierte en literatura”.
} 
[...] Vislumbré que el conjunto de las novelas de Enrique Vila-Matas podían ser leídas como una obra única en la que se narra -desde distintos ángulos- la historia imaginaria de la literatura contemporánea. Sus novelas son una reconstrucción sarcástica y apasionada de las guerras, los furores, los lugares, los sueños, las obsesiones de los escritores, los lectores, los traductores, los libreros, los editores o los críticos; como si sus personajes formaran parte de la tripulación maldita del Pequod y persiguieran al Moby Dick del siglo XXI.

4) Finalmente, hay que subrayar su faceta de creador de una serie de especímenes que ya pertenecen a la amplia comunidad de sus lectores. Es el caso de los shandys -que aúnan vida y literatura de forma tan explosiva como vanguardista-, bartlebys -imposibilitados de escribir-, montanos -enfermos de literatura-, pasaventos -deseosos de desaparecer a toda costa, y de ahí sus continuos seudónimos y viajes-, lancastres -arrepentidos de lo que han escrito- u oblómovs -vagos por antonomasia y, por ello, de espíritu artístico, en alusión al personaje mitificado por el ruso Goncharov.

Una vez probados los vínculos existentes entre Vila-Matas y excelentes autores transoceánicos de diferentes generaciones, paso a destacar las claves de su poética que han concitado mayor admiración.

\section{EPOPEYA Y “ARTE TERMITA” FRENTE A DISCURSO BÍBLICO}

Recordemos los dos tipos de relato descritos por Erich Auerbach en $\mathrm{Mi}$ mesis: La Biblia, narrativa total y múltiple, que avanza en el tiempo con un núcleo claro y un sentido teleológico, y la epopeya, epifánica, de carácter voluntariamente menor y ceñida en el tiempo y el espacio. Roland Barthes las diferencia con claridad en El placer del texto:

[...] Hay dos regímenes de la lectura: una va directamente a las articulaciones de la anécdota, considera la extensión del texto, ignora los juegos del lenguaje (si leo a Julio Verne voy rápido: pierdo el discurso, y, sin embargo, mi lectura no está fascinada por ninguna "pérdida" verbal, en el sentido que esta palabra puede tener en espeleología); la otra lectura no deja nada: pesa el texto y ligada a él lee, si así puede decirse, con aplicación y ardientemente, atrapa en cada punto del texto el asíndeton que corta los lenguajes, y no la anécdota $(1989$, p. 22). 
En esta misma línea se entiende la distinción realizada por el crítico de cine Manny Farber en "White Elephant Art vs. Termite Art", donde distingue un "arte elefante blanco" frente a un arte "termita", y hecho que lleva a Vila-Matas a escribir en "Una novela no elefante" (2012 julio):

[...] El arte elefante blanco está relacionado "con esa manera que tienen algunos de tratar sus obras como un espacio potencial para una creatividad digna de elogio, de aplauso académico y premio, sobre todo de premio: ese esforzarse en ser grande, en tratar temas importantes, etcétera. Me quedo, sin dudarlo, con el arte termita. Algunos ejemplos de termitismo ligero para quien quiera planificar su verano: No leer, de Alejandro Zambra (AlphaDecay); [...] ¡Ah, el mundo de las diminutas termitas que pacientemente corroen la tarima sobre la que se apoya el voluminoso y admirado elefante blanco!

Del mismo modo, el catalán encuentra la conjunción perfecta de estos dos modos de crear en "Doctor Finnegans y Monsieur Hire" (2009b), reseña de Mis dos mundos de Sergio Chejfec:

El argentino Sergio Chejfec se debate entre las estrategias novelísticas presumiblemente antagónicas de Joyce y de Simenon. Entre la narración como arte y como discurso. El mundo interior y el exterior. En su novela Mis dos mundos se muestra cómplice de ambas tendencias y las combina, abriéndose a prometedores territorios literarios. [...] En cierto sentido, los libros esencialmente narrativos puede que sean los gemelos idiotas de los pretenciosos libros que tratan de acercarse al arte verdadero. Pero está en el fondo todo entrelazado y no tiene por qué haber una división radical, tan sólo una lábil frontera. [...] Chejfec está más cerca de la ruta Finnegans, pero aborda la historia de su novela mediante un hilo Hire; es decir, que se atiene a las convenciones de lo narrativo, aunque al mismo tiempo pone en marcha desde dentro -como dinamita pura- un mecanismo narrativo que, por su lectura implacable de la realidad, nos acerca a la verdad muda del vago flotar kafkiano. [...] Mis dos mundos es Finnegans con el rostro de Hire, lo que abre un espacio muy interesante para la novela del futuro.

Siguiendo esta línea de pensamiento se entiende cómo, para los autores de estirpe vilamatiana, la escritura se revela siempre como mentira. Haciendo suyo el postulado según el cual un narrador debe poner de manifiesto en todo momento el trampantojo que constituye todo objeto artísti-

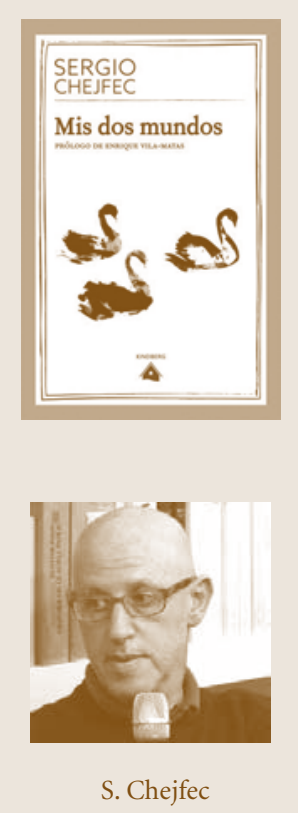


co (Baudrillard, 1997, p. 29), acogen con gusto para sus obras la idea de $L a$ letteratura come menzogna, título ya clásico de Giorgio Manganelli. Así lo afirma Villoro en "Los shandys del Templo Mayor" (2004): "Desde su título, la novela Impostura es un programa estético". Por ello, también, se establece una conexión de Vila-Matas con César Aira, apuntada por Bolaño cuando comenta: "El único escritor actual con el que se le puede comparar [a Aira] es el barcelonés Enrique Vila-Matas. Aira es un excéntrico, pero también es uno de los tres o cuatro mejores escritores de hoy en lengua española" (2004, p. 137). Y esto, debido a que las obras de Aira defienden el fin del arte de contar en favor de nuevos procedimientos escriturales (entre los que la imagen adquiere un papel crucial, así como el voluntario error, la intrascendencia y la improvisación), y hecho que lleva al argentino a presentarse no como un autor de novelas, sino como un artista que escribe accidentalmente libros.

\section{DESAPARICIÓN DE LA LITERATURA}
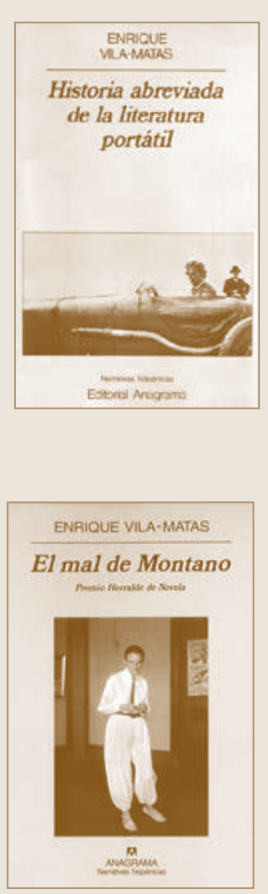

Recurro a "Nota sobre Walt Whitman" de Borges, para destacar la tradición en que se inscriben textos vilamatianos capitales como la trilogía conformada por Historia abreviada de la literatura portátil, Bartleby y compañía y Aire de Dylan: “Góngora, creo, fue el primero en juzgar que un libro importante puede prescindir de un tema importante: la vaga historia que refieren las Soledades es deliberadamente baladí. [...] A Mallarmé no le bastaron temas triviales; los buscó negativos: la ausencia de una flor o de una mujer, la blancura de la hoja de papel antes del poema" (2004, p. 249).

Si Monterroso reinterpretó en Lo demás es silencio la máxima nulla dies sine linea como "anula una línea cada día" (1986, p. 134), se comprenderá la impronta de este concepto en un autor preocupado por la desaparición de la literatura en todos sus componentes. Amparado en la tradición de $L a$ escritura del desastre de Maurice Blanchot, donde leemos "es menester repetirlo: el desastre des-escribe" (1990, p. 14), y en la de Barthes y Foucault, con sus respectivas proclamas sobre "la muerte del autor", Vila-Matas abre $E l$ mal de Montano, significativamente, con un epígrafe del mismo Blanchot: “¿Qué haremos para desaparecer?” (2002a, p. 9).

De ahí su admiración por escritores del no como Monterroso, Juan Carlos Onetti, Felisberto Hernández, Juan Rodolfo Wilcock y, especialmente, Juan Rulfo, a los que cita repetidamente en sus textos. De ahí también su deseo -especialmente intenso en la que denomina como su "etapa del sin- 
sentido"- de desarrollar una obra a partir de notas a pie como las que componen Bartleby y compañia, vinculadas a un libro invisible. Estas experiencias se encuentran en la línea de pensamiento borgesiano, por la que esbozar tramas imaginarias resulta mucho más valioso que completarlas, y que llevó al argentino, junto a su amigo Bioy Casares, a defender en el prólogo a Cuentos breves y extraordinarios los relatos integrados en esta antología, apostillando que, frente a ellos, "lo demás es episodio ilustrativo, análisis psicológico, feliz o inoportuno adorno verbal" (1967, p. 8).

\section{MOVIMIENTO PERPETUO, PERO LENTO}

Otro aspecto que une a Vila-Matas a ciertos escritores latinoamericanos viene dado por la importancia que adquiere en sus obras la idea de movimiento, opuesto por definición a los estados fijos y permanentes. Ya apunté arriba cómo estos autores remiten a la figura del flâneur, pues sus páginas pueden ser vistas como verdaderos periplos existenciales en los que, a cada paso, el sujeto se permite el lujo de detenerse y comentar los más ínfimos y variados detalles de lo que ve. Ilustres defensores del vagabundeo, harían suyas las palabras del narrador de Der Spaziergang de Robert Walser: "Ohne Spazieren wäre ich tot, und meinen Beruf, den ich leidenschaftlich liebe, hätte ich längst preisgeben müssen” [Sin pasear estaría muerto y mi profesión, que amo apasionadamente, estaría aniquilada] (traducción mía) (1998, p. 55).

El mejor ejemplo de este espíritu paseante se encuentra en el ya citado Movimiento perpetuo de Monterroso, iniciado con el epígrafe "La vida no es un ensayo, aunque tratemos muchas cosas; no es un cuento, aunque inventemos muchas cosas; no es un poema, aunque soñemos muchas cosas. El ensayo del cuento del poema de la vida es un movimiento perpetuo; eso es, un movimiento perpetuo" (1981, p. 9). Pero igualmente podemos citar en esta línea La vuelta al día en ochenta mundos o Último round de Cortázar, Cuaderno de escritura de Salvador Elizondo, Prosas apátridas de Julio Ramón Ribeyro, Manual del distraído de Alejandro Rossi, El arte de la fuga y El viaje de Sergio Pitol, Los incompletos, Baroni: un viaje y Mis dos mundos de Sergio Chejfec. Nos encontramos, pues, ante obras conscientes del valor de una literatura voluntariamente errante pero nunca errática, ya que convierten el estilo en único principio unificador de su escritura. 


\section{HÍBRIDOS GENÉRICOS}

Las mejores estructuras para plasmar estos pensamientos se revelan cercanas al concepto de rizoma. Carentes de eje, insisten en la discontinuidad de sus componentes para ofrecer la caleidoscópica visión de una realidad que reconocen tan compleja como inextricable. Destaco, en este sentido, el amplio reconocimiento recibido por Dietario voluble desde el momento de su aparición, reflejo de cómo actualmente se dan las condiciones para que estas composiciones adquieran el lugar que merecen en la historia de la literatura.

El camino de su canonización no ha sido fácil. Este hecho no ha impedido, sin embargo, que algunos de los mejores autores en español, cercanos al espíritu festivo y experimental de la miscelánea, se hayan atrevido desde muy temprano a practicarla. Es el caso de Alejandro Rossi, quien defendía la libertad genérica en la "Advertencia" de Manual del distraído:
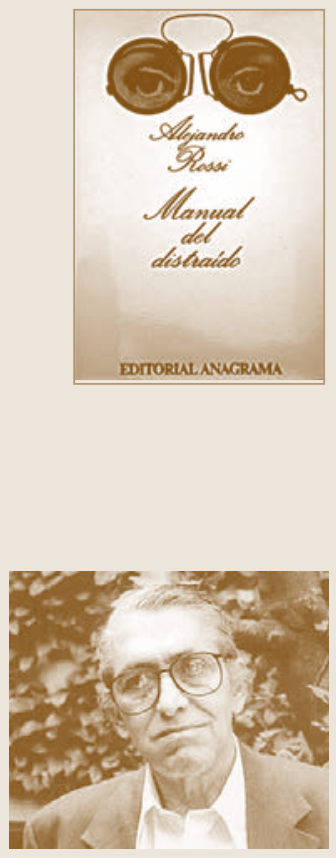

El Manual del distraído nunca se castigó con limitaciones de género: el lector encontrará aquí ensayos más o menos canónicos y ensayos que se parecen más a una narración. Y también descubrirá narraciones que incluyen elementos ensayísticos y narraciones cuyo único afán es contar una pequeña historia. Tampoco están ausentes las reflexiones brevísimas, las confesiones rápidas o los recuerdos. Un libro, en todo caso, que huye de los rigores didácticos pero no de la crítica, y que fervorosamente cree en los sustantivos, en los verbos y en los ritmos de las frases. Un libro -lector improbable- que expresa mi gusto por el juego, por la moral, por la amistad y, sobre todo, por la literatura. Léelo, si es posible, como yo lo escribí: sin planes, sin pretensiones cósmicas, con amor al detalle (1997, p. 31).

Ante esta declaración, se entiende que Vila-Matas comentara en entrevista con Armando G. Tejeda (2001): "Hay escritores, como Alejandro Rossi, que yo considero de primera fila: son los que aspiran a la obra maestra, que es a lo que aspiro yo"3. En cuanto a su propia poética, en la entrada

\footnotetext{
${ }^{3}$ Así, en "Lo que dije de Alejandro Rossi en Barcelona” (1997), define Manual del distraído con términos absolutamente aplicables a su propia obra: "Es antisolemne. 2) Ha sido definido -con acierto- como un libro que es un baúl de viajes, recuerdos, ensayos e invenciones. 3) Es un libro portátil. 4) Es un libro inclasificable a diferencia de la vulgaridad aplastante de la narrativa española actual, donde son pocos los que arriesgan; todo son novelas, que para eso está el mercado que las compra. 5) Es un libro que desbloquea las convencionales barreras y abre la zona de la sorpresa. 6) Es un libro que vive en la frontera y que es como una caja. Nos recuerda Manual
} 
68 de Bartleby y compañía retoma una frase de Kafka para explicar lo que ocurre en el proceso de escritura de lo que él llama "este diario por el que navego a la deriva": "Cuanto más marchan los hombres, más se alejan de la meta. [...]. Piensan que andan, pero sólo se precipitan -sin avanzar- en el vacío. Eso es todo" [...] Sólo sé que para expresar ese drama navego muy bien en lo fragmentario y en el hallazgo casual o en el recuerdo repentino de libros, vidas, textos o simplemente frases sueltas que van ampliando las dimensiones del laberinto sin centro" (2001, p. 150). En "Aunque no entendamos nada" retoma el tema de la estructura de lo que pretende escribir, para lo que defiende el formato del odradek: "Y yo aún no sé muy bien de qué tratarán las páginas de este ensayo que acabo de iniciar. Seguramente intentaré exponer en él mi visión de ese absurdo cargado de sentido que es el mundo y lo haré valiéndome de una estructura odradek, una estructura literaria que adquiera la forma de ready-made, de uno de esos objetos híbridos e inútiles" (2004a, p. 11). En este sentido, se entiende el valor de la pregunta que se hace Roberto Bolaño en "El último libro de Vila-Matas", reseña de Bartleby y compañía fundamental para comprender este aspecto de la poética vilamatiana: "[...] ¿Estamos ante una novela, ante una colección de medallones literarios y antiliterarios, ante un libro misceláneo que escapa a las categorías preestablecidas, ante un diario de vida del autor, ante un entrelazamiento de crónicas periodísticas? [...] Tal vez estamos ante una novela del siglo XXI, es decir una novela híbrida, que recoge lo mejor del cuento y del periodismo y la crónica y el diario de vida [...]” (2004a, p. 286).

\section{INTERTEXTUALIDAD}

Recuerdo, para comenzar este apartado, algunas frases de "Alocución en Monterrey", texto leído por el autor en la Cátedra Anagrama de la universidad mexicana:

que, al igual que en una caja, en un libro podemos depositar ensayos, relatos, digresiones, sátiras, reflexiones, recuerdos, homenajes a maestros y hasta aforismos de Lichtenberg. 7) Se exalta, en la mejor línea de Walter Benjamin, lo infinitamente pequeño. El libro está lleno de minucias, de enormes minucias, que diría Chesterton. 8) En el libro la unidad es más estilística que temática. 9) El estilo organiza el punto de vista y hay en él -como ha dicho Octavio Paz-ligereza y elegancia ("Pienso en la elegancia desesperada de una flor en el ojal"). 10) Junto a El arte de la fuga de Sergio Pitol es el mejor libro que he leído en los últimos años”.

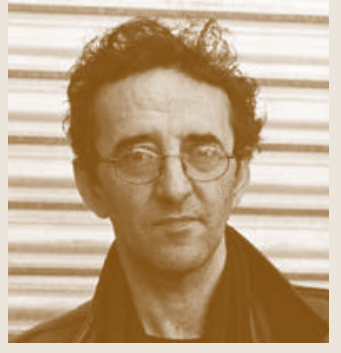

R. Bolaño 
Puede parecer paradójico, pero he buscado siempre mi originalidad de escritor en la asimilación de otras voces. Las ideas o frases adquieren otro sentido al ser glosadas, levemente retocadas, situadas en un contexto insólito. [...] Recuerdo en este sentido el libro de ensayos de Juan García Ponce La errancia sin fin, donde este crucial autor mexicano enuncia su concepto de la literatura como discurso polivalente en el cual los autores se funden y se pierden en el espacio anónimo de la literatura. Ya en su propia obra, desde el principio, García Ponce empleó la intertextualidad para crear homenajes a sus autores favoritos y de esa forma fundir su literatura con la de ellos (2008, n.p.).

En otra ocasión se burla de su propio mal, la enfermedad de la literatura, apropiándose, como señala Roberto Brodsky en "Crónica de un hombre enfermo de literatura", del término "literatosis" acuñado por Juan Carlos Onetti:

Pero, ¿qué significa estar enfermo de literatura? Ante todo, significa referir cada incidente o acontecimiento de la vida, por nimio que sea, a la condición de frase leída, de texto recordado, de escritor habitado anteriormente por ese mismo hecho convertido en producto de la imaginación. El uruguayo Juan Carlos Onetti llamaba "literatosis" a esta incontinencia bibliomaníaca, capaz de transformar el vuelo de una mosca en la duda de Hamlet y reconstruir de paso la biblioteca del mundo mediante este breve impasse shakespereano. El término es tan exacto que el narrador de Vila-Matas lo recupera para burlarse de su propio mal, sabiendo que en la burla ya está la cura capaz de alentarlo y hacer aparecer su enfermedad como lo que es en verdad. Es decir: una batalla por los derechos de la ficción $(2007, \text { p. 258 })^{4}$.

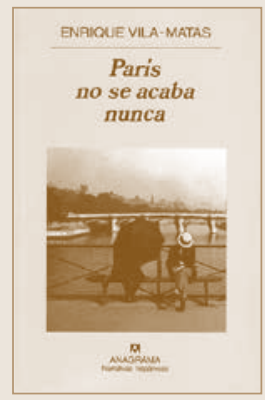

Es lógico que, en este apartado, se repitan las alusiones a la figura de Borges, del que señala en París no se acaba nunca: "Leerlo fue toda una revelación para mí” (Vila-Matas 2003b, p. 147). Más adelante comentará la magia inherente al argumento de "Pierre Menard, autor del Quijote", relato que vuelve a citar en Dietario voluble con las siguientes palabras: "Pierre Menard, que reescribió el Quijote y al parecer es pariente mío" (2008, p. 111).

\footnotetext{
${ }^{4}$ Teniendo presente que toda asociación textual parte de la enciclopedia del lector y del contexto interpretativo, Vila-Matas considera intertextualidad y metaliteratura conceptos redundantes. Como señala a Susana Arroyo y José Javier Fernández Díaz: "La intertextualidad remite a algunos críticos obtusos a la metaliteratura, que es un género o práctica que en realidad no existe. Yo al menos siempre he tenido la impresión de hacer simplemente literatura, no metaliteratura" (2008, p. 203).
} 
En relación al tema que nos ocupa en estas páginas, ofrezco un ejemplo de las complejas intersecciones que se producen en el ejercicio transtextual vilamatiano a partir de El mal de Montano, donde un personaje demuestra su apropiación de Borges a partir de un libro sobre el argentino -El factor Borges, de Alan Pauls- encontrado en la casa del escritor Rodrigo Fresán:

Me habría encantado ser visitado por los recuerdos personales de Alan Pauls, por los recuerdos del día en que escribió "Segunda mano", un capítulo de su libro El factor Borges. Hay en lo que acabo de decir un claro deseo en el fondo menos extraño que el deseo de ser piel roja de Kafka. Lo que a nadie debe sorprender es que admire "Segunda mano", pues se trata de una reflexión especialmente aguda en torno del parasitismo literario del Gran Borges, en torno a un tema -el del vampirismo libresco- que en las calles de Nantes me había mantenido muy inquieto y preocupado y que se solucionó de golpe al convertirme en parásito literario de mí mismo, descubrimiento feliz que tal vez podría haberme llegado antes de haber sabido aquel día de la existencia de El factor Borges (2002a, p. 119)

\section{JUEGOS CON EL "YO"}

"A veces tengo la impresión de que surjo de lo que he escrito como una serpiente surge de su piel", leemos en El viaje vertical (Vila-Matas 1999a, p. 29). Esta frase explica uno de los aspectos más fascinantes en la constitución de la obra vilamatiana: el juego de revelación/ocultamiento del "yo" al que nos somete continuamente tanto en relación a su figura como a la de sus personajes. En este sentido parece seguir la senda de Monterroso, quien ya en el título de La letra e: fragmentos de un diario se refiere a sí mismo como una pluralidad de individuos:

Escribiéndolo [el libro] me encontré con diversas partes de mí mismo que quizá conocía pero que había preferido desconocer: el envidioso, el tímido, el vengativo, el vanidoso y el amargado; pero también el amigo de las cosas simples, de las palabras, de los animales y hasta de algunas personas, entre autores y gente sencilla de carne y hueso. Yo soy ellos, que me ven y a la vez son yo, de este lado de la página o del otro, enfren-

\footnotetext{
${ }^{5}$ Por cierto, Pauls es responsable de "Razones para envidiar a Vila-Matas" (2006), una de las
ás certeras lecturas sobre nuestro autor basada en la tríada mundo, primera persona y estilo, con

${ }^{5}$ Por cierto, Pauls es responsable de "Razones para envidiar a Vila-Matas" (2006), una de las
más certeras lecturas sobre nuestro autor basada en la tríada mundo, primera persona y estilo, con la que presentó Doctor Pasavento en la Feria del Libro de Buenos Aires.
}

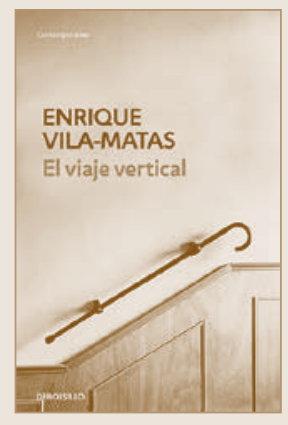


tados al mismo fin inmediato: conocernos, y aceptarnos o negarnos; seguir juntos, o decirnos resueltamente adiós $(1987$, p. 7$)$.

Ciudadanos Zelig de la república de las letras, la reivindicación de la máscara será una constante en estos escritores. Así se aprecia en "Te conozco, mascarita", incluido en Movimiento perpetuo y de nuevo aplicable al autor de Bartleby y compañía: "El humor y la timidez generalmente se dan juntos. Tú no eres una excepción. El humor es una máscara y la timidez otra. No dejes que te quiten las dos al mismo tiempo" (Monterroso, 1981, p. 51). En "Intertextualidad y metaliteratura" (2008) Vila-Matas abogará por este mismo recurso de ocultamiento -"Se trata de ser muchos y construirse una personalidad a base de ser todos los hombres"-, mientras en "¿Por qué es usted tan posmoderno?" subraya: "No hay mejor pseudónimo o forma de ocultarse que firmar con el nombre propio" (2002b, p. 24).

Este hecho explica, asimismo, su interés por el tema del Doppelgänger, reflejado en obras como Historia abreviada de la literatura portátil, donde uno de los rasgos identificativos de los miembros de la conspiración shandy viene dado porque poseen una "tensa convivencia con la figura del doble" (Vila-Matas, 1985, p. 13); París no se acaba nunca, que comienza con un concurso de dobles de Hemingway; o Doctor Pasavento, en el que el protagonista adquiere, sucesivamente, los nombres de Dr. Pasavento -doctor en psiquiatría-, Pynchon -por el escritor real que desapareció de escena voluntariamente-, Ingravallo o Emmanuel Bove.

La necesaria ocultación del autor y su rechazo de la fama explica, asimismo, que Vila-Matas no sea asiduo de congresos y homenajes a su obra, haciéndose eco de la walseriana sentencia según la cual "que un escritor se convierta en alguien no hace sino degradarlo a la condición de limpiabotas" (2005a, p. 8). De ahí su admiración por el escritor peruano Enrique Prochazka, al que en "Plan para el más allá" (2006) retrata como el artista perfecto por su defensa de la desaparición y el vagabundeo:

Días después me encontré con la respuesta de Prochazka en uno de los blogs peruanos y leí fascinado: "Abrigo la teoría de que uno tiene éxito porque se agita como loco, o logra que los demás se agiten como locos por uno, o bien los demás lo obligan a uno a agitarse como loco. Según esta noción, a mis textos les sucede lo que les sucede porque yo no me agito. De hecho, escribir estas líneas ya me parece acercarme demasiado a la visibilidad [...]. Vivo en una especie de distante Sydney del espíritu, que se llama Lima. Camino un sábado por la noche de Magdalena a Chacarilla, pasando por todos los sanantonios y centros culturales y 
cafés, y literalmente no conozco a nadie, y nadie me saluda ni conoce mi cara. Me borré en paz, hace años. Entro al Virrey lleno de clientes, compro un libro, dos libros, salgo del Virrey: nadie sabe quién soy. Me borré....".

Así, la ausencia voluntaria de una identidad cierta para el autor explica que, en la portada de Dietario voluble, aparezca fotografiado de espaldas, hecho con el que parece advertir: "el de aquí dentro soy y no soy yo", y, sobre todo, "aborrezco las mitificaciones sobre individuos reales". Pero esto, obviamente, no le impide recurrir obsesivamente a la figura del escritor, por lo que sus amigos aparecen continuamente en sus obras. Es el caso, por ejemplo, de Sergio Pitol, al que presenta en "El fondo eterno" escribiendo en un lenguaje cabalístico y perfecto, y que en París no se acaba nunca lidera una excursión a una librería que solía frecuentar cuando Vila-Matas vivió en la ciudad gala: "Sergio Pitol se convirtió de inmediato en el jefe de la expedición al inmueble de la Ruede Littré. Fue el quien prácticamente nos arrastró a ese lugar" (2003b, p. 151). Lo importante de esta anécdota, por supuesto, no estriba en hallar la ubicación del lugar donde una vez se oyó a Borges, sino en los comentarios vertidos sobre el veracruzano, tan significativos como los siguientes: "De pronto me pareció que él [Pitol] se estaba moviendo como si estuviera dentro de uno de sus relatos" (p. 152); o, en la misma página, "Nos fuimos de allí con la impresión de haber estado más cerca que nunca de la invisible verdad".

\section{“REALISMO INTERIOR"}

Quiero concluir esta enumeración apuntando un rasgo esencial en el universo creativo de Vila-Matas. Me refiero, lógicamente, a su defensa del "realismo interior", descrita con lucidez en "Inventar lo real" (2007):

[...] La tendencia más interesante de la narrativa actual, dentro de un imaginario espacio iberoamericano, recoge la sustitución del fantaseo lírico del realismo mágico por un surrealismo mucho más subversivo, atraído por una imaginería de lo grotesco y a menudo encaminado a una representación satírica de la realidad; un surrealismo que en su deriva más interesante se adentra en lo que Augusto Monterroso definió como "el realismo interior". Así, Sergio Pitol, Augusto Monterroso, Fernando Vallejo, Javier Marías y Julio Ramón Ribeyro, entre otros, se erigirían en los exploradores de los nuevos caminos abiertos por lo más 

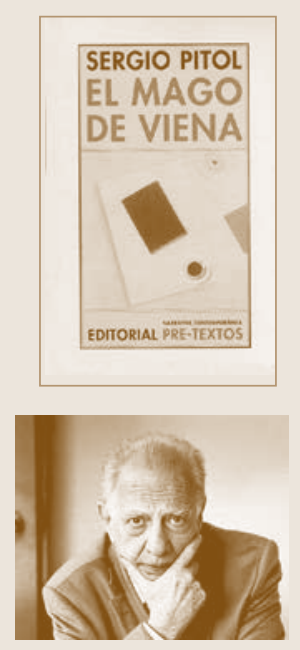

S. Pitol granado de las nuevas generaciones, plantadas al final del camino en un abismo muy seriamente atractivo [...].

Esta meditación parece continuarse en las líneas que dedica Reinaldo Laddaga (2000) al "refinamiento absurdo" característico de El mago de Vie$n a$, de Pitol y, con este título, a la obra de otros apellidos tan relevantes en las letras contemporáneas como los de Aira, Bellatin o Francisco Hinojosa:

[...] Se trata de textos poblados, continuamente, como por una obsesión, por personajes a la vez excéntricos y modestos, indiferentes a sus entornos aunque bañados en una atmósfera de vaga desesperación, pequeños monstruos humanos, marionetas trepidantes, o, para usar una expresión del mismo Enrique Vila-Matas que Pitol cita, extrañas formas de vida ${ }^{6}$.

Esto explicaría la elogiosa reseña escrita por nuestro autor sobre Pablo Palacio en "El Antonin Artaud ecuatoriano" (2001), donde habla de su descubrimiento del autor a través de su amigo Leonardo Valencia, o sus continuas reflexiones sobre los argentinos Macedonio Fernández, Juan Rodolfo Wilcock, Rodolfo Fogwill o el cuasi "nacional" Gombrowicz. En todos estos autores reconocemos una "ferocidad" vital vinculada al ardor con el que persiguen la página perfecta.

Sin duda, uno de los mejores representantes de esta estirpe es Roberto Bolaño, al que Vila-Matas dedicó reflexiones fundamentales como las presentes en "Música para malogrados" (2012): "uno a veces cree ver señales para seguir navegando, porque vislumbra los casos de un puñado de escritores que captaron la gravedad del momento y lo que escribieron fue enfermizo y canibalesco, absurdo y exasperado, pero paradójicamente también feliz y auténtico. [...] Algunos de esos grandes malogrados me vienen de

${ }^{6}$ Vila-Matas, en este sentido, se muestra como uno más entre los "raros" retratados por Pitol en El mago de Viena: "Los raros, como los nombró Darío, o "excéntricos", como son ahora conocidos, aparecen en la literatura como una planta resplandeciente en las tierras baldías o un discurso provocador, disparatado y rebosante de alegría en medio de una cena desabrida y una conversación desganada. Los libros de los "raros" son imprescindibles, gracias a ellos, a su valentía de acometer retos difíciles que los escritores normales nunca se atreverían. Son los pocos autores que hacen de la escritura una celebración. [...] Yo adoro a los excéntricos. [...] Ramón del Valle-Inclán, Virgilio Piñera, Thomas Bernhard, Augusto Monterroso, Flann O’Brien, Raymond Roussel, Marcel Schwob, Mario Bellatin, César Aira, Enrique Vila-Matas son excéntricos ejemplares, como todos y cada uno de los personajes que habitan sus libros, y por ende las historias son diferentes de las de los demás” (2008, p. 302). 
inmediato a la memoria: Beckett, Bernhard, Bolaño" o "Un plato fuerte de la China destruida" (2003a), donde describe al amigo recién desaparecido como "este calígrafo del sueño que ha dejado a sus lectores literatura pura y dura, una obra de creación seria y sin medias tintas, un plato fuerte de la China destruida". En este mismo ensayo revela cómo, por Bolaño, se sintió obligado a elevar su propio nivel de excelencia creativa:

[...] gracias a que tenía la impresión de que Roberto lo leía todo pasé a vivir en un estado de constante exigencia literaria, pues él había colocado el listón muy alto y no deseaba decepcionarle, por ejemplo, con algún texto descuidado, con uno de esos escritos en los que, por mil motivos distintos, uno no arde lo suficiente o, lo que es lo mismo, no pone toda la carne en el asador [...].

Así, aunque en "Bolaño en la distancia" (1999b) distingue sus respectivas poéticas -él se define como un artista de la levedad frente a la multiplicidad que permea la obra del chileno-, acaba viéndose voluptuosamente atraído por la sombra del "otro", del que jamás puede -ni quiere- alejarse, y con el que comparte ADN creativo: "[...] Es posible -me digo ahora- que Masoliver haya acertado al considerarme un lector idóneo para la novela de Bolaño. De hecho, me siento muy cercano a toda la obra del escritor chileno. Es posible incluso que sea el escritor que más se parece a mí, o viceversa: soy el escritor que más se parece a Bolaño. La causa tal vez resida en la a veces casi aplastante coincidencia en cuanto a gustos y rechazos literarios [...]".

En consonancia con esta situación, vayan dos testimonios de la admiración sentida por Bolaño hacia Vila-Matas. En "Osvaldo Lamborghini: mártir", el autor de 2666 reconoce el impacto que le provocó la lectura de $\mathrm{La}$ asesina ilustrada:

Hay libros que inspiran miedo. Miedo de verdad. Más que libros parecen bombas de relojería o animales falsamente disecados dispuestos a saltarte al cuello en cuanto te descuides. Esta experiencia yo sólo la he tenido en dos ocasiones. La primera fue hace mucho tiempo, en 1977 o 1978; leía entonces una novela breve en una de cuyas páginas se advertía al lector que a partir de ese momento podía morirse. Es decir: que se podía morir literalmente, caerse al suelo y no levantarse. La novela era La asesina ilustrada, de Enrique Vila-Matas, y que yo sepa ninguno de sus lectores se murió aunque muchos salimos transformados después de su lectura, con la certeza de que algo había cambiado para siempre en nuestra relación con la literatura [...] (2004, pp. 141-142). 
En la misma línea se encuentra el texto póstumo "Poema para EVM". Con él, en homenaje a la radical experiencia literaria llevada a cabo por ambos escritores ${ }^{7}$, deseo concluir mi análisis, en el que espero haber probado la relación existente entre Enrique Vila-Matas y algunos de los más relevantes escritores latinoamericanos de los siglos XX y XXI:

Qué lugar es ése al que nos llevarán nuestras palabras, las bellas durmientes, por caminos a menudo distintos, qué eriazo,

qué infierno, qué nos espera allí, Enrique, en esa blancura en la que nos reuniremos finalmente, qué aullidos, qué silencio,

qué permutaciones nos aguardarán cuando hayamos atravesado todo lo que hay que atravesar, cuando nos hayamos despojado de todo, qué olvidos, qué.

En algún lugar infinito se esconde, en un tiempo que nos es ajeno, que ni siquiera nos molestamos en mensurar, allí, donde tiene una casa nuestro terror de alquiler (Haasnoot, 2008).

\section{REFERENCIAS}

Arroyo, S. y Fernández Díaz, J. J. (2008). “Viaje o literatura? (entrevista anticipatoria con Enrique Vila-Matas)”. Cartaphilus 3, 199-204.

Barthes, R. (1989). El placer del texto. Madrid: Siglo XXI [1973].

Baudrillard, J. (1997). Illusion, désillusion esthétiques. Paris: Sens \& Tonka.

Blanchot, M. (1990). La escritura del desastre. Caracas: Monte Ávila [1980].

Bolaño, R. (2004). Entre paréntesis. Barcelona: Anagrama.

Borges, J. L. (2004). Obras completas I (1923-1949). Barcelona: Emecé.

Borges, J. L. y Bioy Casares, A. (1967 [1953]). Cuentos breves y extraordinarios. Buenos Aires: Santiago Rueda.

Brodsky, R. (2007). "Crónica de un hombre enfermo de literatura". En VilaMatas portátil. Un escritor ante la crítica. Margarita Heredia Ed. Barcelona: Candaya. 257-266.

Costa, F. (2006, enero 28). "La literatura es un oficio peligroso. Entrevista a Enrique Vila-Matas" Revista N, suplemento de Clarín.

Domínguez Michael, C. (2008, octubre). "Dietario voluble, de Enrique VilaMatas y Vila-Matas portátil. Un escritor ante la crítica, de Margarita Heredia (Ed.)", Letras Libres.

\footnotetext{
${ }^{7}$ Esta se encuentra apuntada, asimismo, en Doctor Pasavento: "No somos de aquí. Y sólo la literatura parece ocuparse con seriedad de nuestro espanto" (Vila-Matas 2005a, p. 315).
} 
Esquinca, B. (2003, abril 13). “Las conspiraciones del novelista. Entrevista con Enrique Vila-Matas”. Mural, Guadalajara.

Fresán, R. (2001, julio 1). "Historia abreviada de un Vila-Matas portátil”. Radar, suplemento de Página 12.

Haasnoot, E. (2008). Bolaño cercano. Documental. Disponible en http://www. youtube.com/playlist?list=PLFF51E9387C0AD888 (12/06/2012).

Iwasaki, F. (2010, marzo 14). "Continuidad de los museos", $A B C$.

Laddaga, R. (2000). "Un refinamiento absurdo. Enumeraciones de Sergio Pitol” Ciberletras, 2. En http://www.lehman.cuny.edu/ciberletras/v01n02/ Laddaga.htm (12/06/2012).

Monterroso, A. (1981 [1972]). Movimiento perpetuo. Barcelona: Seix Barral. . (1986 [1978]). Lo demás es silencio. La vida y la obra de Eduardo Torres. Jorge Ruffinelli Ed. Madrid: Cátedra.

. (1987). La letra e: fragmentos de un diario. Madrid: Alianza.

Nettel, G. (2008). "Paseante casual”. En http://www.enriquevilamatas.com/ escritores/ escrnettel1.html (12/06/2012).

Pauls, A. (2006). "Razones para envidiar a Vila-Matas”. En http://www. enriquevilamatas.com/escritores/escrpauls1.html (12/06/2012).

Piglia, R. (2011, abril 9). "Leyendo a Enrique Vila-Matas". En http://leyendoaenriquevilamatas.wordpress.com/2011/04/09/ricardo-piglia-premiode-la-critica-leo-con-mucho-interes-a-vila-matas-a-javier-marias-y-tambien-las-novelas-de-juan-marse (12/06/2012).

Pinto, R. (2001, enero 28). “Bolaño a la vuelta de la esquina”. Las Últimas Noticias.

Pitol, S. (2001). “El Rómulo para Enrique”. En http://www.enriquevilamatas. com/escritores/escrpitoll.html (12/06/2012). . (2008 [2005]). El mago de Viena. En Obras reunidas V. Ensayos. México: FCE.

Rossi, A. (1997). Manual del distraído. Barcelona: Anagrama.

Tejeda, A. G. (2001). "Enrique Vila-Matas: el canon literario español está dictado por las mafias”. Babab, 6. En http://www.babab.com/no06/enrique_vilamatas. htm (12/06/2012).

Vila-Matas, E. (1977). La asesina ilustrada. Barcelona: Tusquets.

. (1985). Historia abreviada de la literatura portátil. Barcelona: Anagrama. . (1992). El viajero más lento. Barcelona: Anagrama.

. (1997, septiembre 21). "Lo que dije de Alejandro Rossi en Barcelona".

La Jornada Semanal.

. (1999a). El viaje vertical. Barcelona: Anagrama.

. (1999b, abril). "Bolaño en la distancia”, Letras Libres.

. (2000). Bartleby y compañía. Barcelona: Anagrama.

. (2002a). El mal de Montano. Barcelona: Anagrama.

. (2002b, septiembre 14). “Por qué es usted tan posmoderno?”, Babelia.

. (2003a, agosto 24). "Un plato fuerte de la China destruida”. En http://

www. enriquevilamatas.com/ textos/textplatofuerte.html (12/06/2012). 
. (2003b). París no se acaba nunca. Barcelona: Anagrama.

. (2004a). Desde la ciudad nerviosa. Madrid: Alfaguara.

. (2004b, febrero 28). "Monterroso en nueve palabras". El País.

. (2004c, diciembre). "En seis horas y cuarto: Witold Gombrowicz

(1904-1969)" Letras Libres.

. (2005a). Doctor Pasavento. Barcelona: Anagrama.

. (2005b, marzo 25). “De lo contrario, Auster sería yo". Letras Libres.

. (2006, enero 17). "Plan para el más allá”. El País, 36.

. (2007, marzo). "Inventar lo real". En http://congresosdelalengua.es/

cartagena/ ponencias/seccion_1/14/vila-matas_enrique. htm (12/06/2012). . (2007, octubre 30). "Entrevista con Enrique Vila-Matas". El País. . (2008, mayo 12). "Intertextualidad y metaliteratura". En http://www.

march.es/ conferencias/anteriores.voz.asp?id=2503 (12/06/2012). . (2008, agosto 1). "Alocución en Monterrey. En http://www.enriquevi-

lamatas.com/textos/ textmonterrey.html (12/06/2012). . (2008). Dietario voluble. Barcelona: Anagrama.

. (2009, octubre 10). “Doctor Finnegans y Monsieur Hire”. El País.

. (2012, junio 2). "Música para malogrados". El País.

. (2012, julio 9). "Una novela no elefante". El País.

Villoro, J. (2004, diciembre 12). "Los shandys del Templo Mayor". Reforma.

Walser, R. (1998 [1917]). Der Spaziergang. Zurich: Suhrkamp. 